Supporting Information

\title{
Self-Healing Solid Polymer Electrolyte Facilitated by a Dynamic Cross-Linked Polymer Matrix for Lithium-Ion Batteries
}

Ye Hyang Jo, Shaoqiao Li, Cai Zuo, Yong Zhang, Huihui Gan, Sibo Li, Liping Yu, Dan He, Xiaolin Xie, Zhigang Xue*
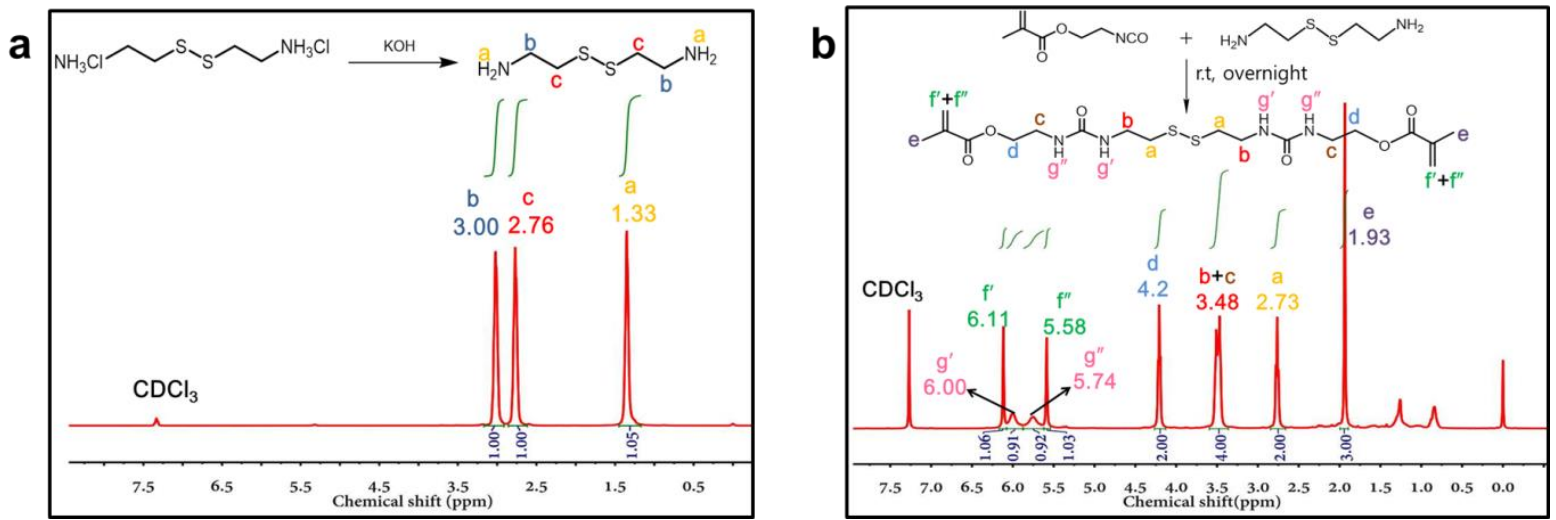

Figure S1. ${ }^{1} \mathrm{H}$ NMR spectra of a) cystamine and b) SSH monomer.
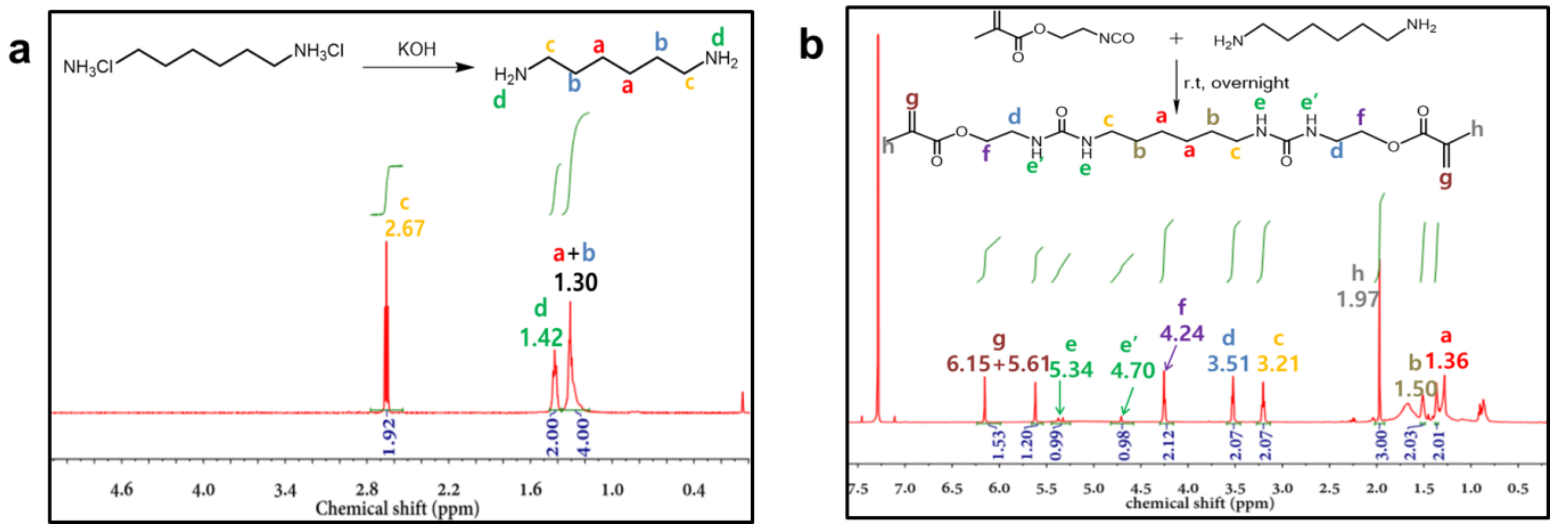

Figure S2. ${ }^{1} \mathrm{H}$ NMR spectra of a) diaminohexane and b) $\mathrm{CCH}$ monomer.

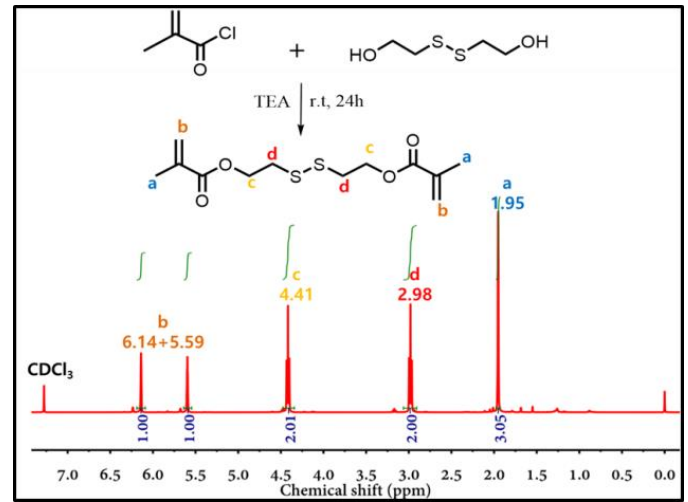

Figure S3. ${ }^{1} \mathrm{H}$ NMR spectrum of the SS monomer. 


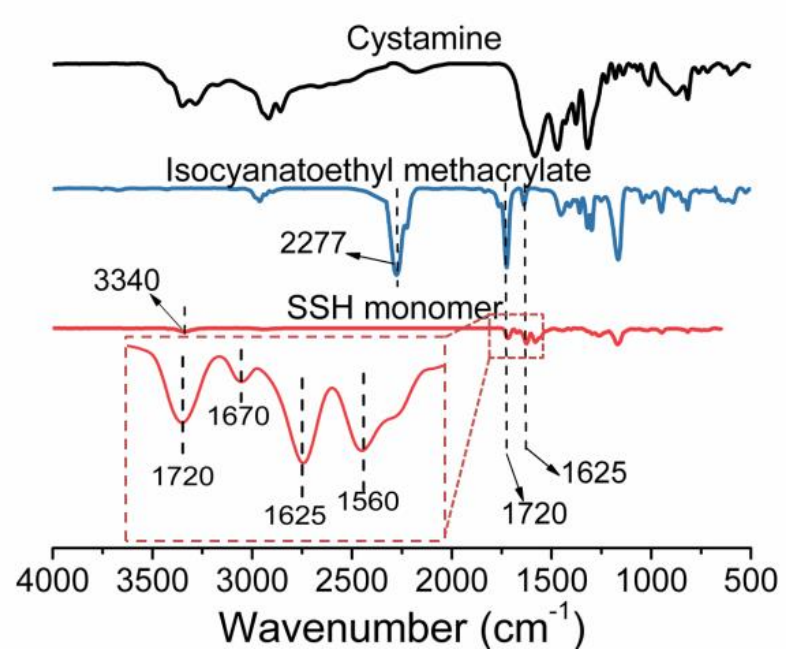

Figure S4. FT-IR spectra of SSH monomer.

The peaks at $1720 \mathrm{~cm}^{-1}$ and $1625 \mathrm{~cm}^{-1}$ are observed for isocyanatoethyl methacrylate, which are ascribed to the absorptions of carbonyl and carbon double bond, respectively. The peak at $2277 \mathrm{~cm}^{-1}$ of isocyanatoethyl methacrylate which is ascribed to the presence of -NCO groups. The peak of $-\mathrm{NCO}$ groups disappeared in the SSH monomer, indicating that the successful reaction between $-\mathrm{NH}_{2}$ of cystamine and $-\mathrm{NCO}$ of isocyanatoethyl methacrylate. In addition, new peaks of $3340 \mathrm{~cm}^{-1}$ and $1560 \mathrm{~cm}^{-1}$ appeared in SSH monomer are the stretching and bending vibrations of secondary amino $(\mathrm{N}-\mathrm{H})$, respectively. The stretching vibration of carbonyl in urea group is located at $1650 \mathrm{~cm}^{-1}$. It can be concluded that the SSH monomer was successfully synthesized. 
a

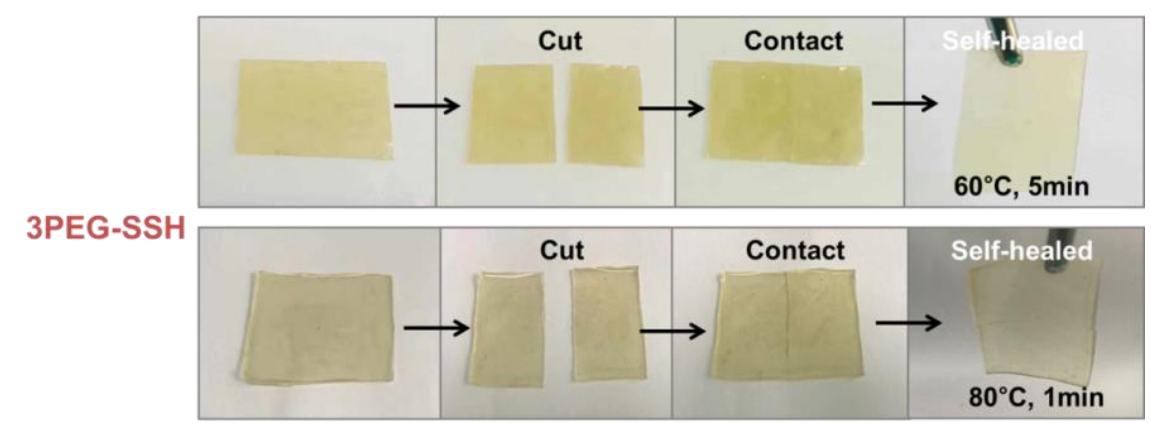

b

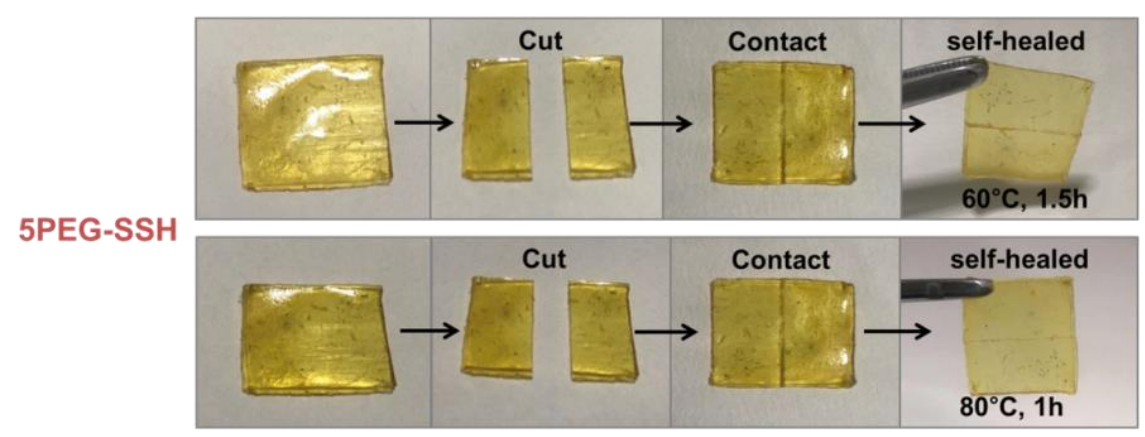

Figure S5. Optical images showing the self-healing process of the a) 3PEG-SSH polymer electrolyte and b) 5PEG-SSH polymer electrolyte at $60{ }^{\circ} \mathrm{C}$ and $80{ }^{\circ} \mathrm{C}$.

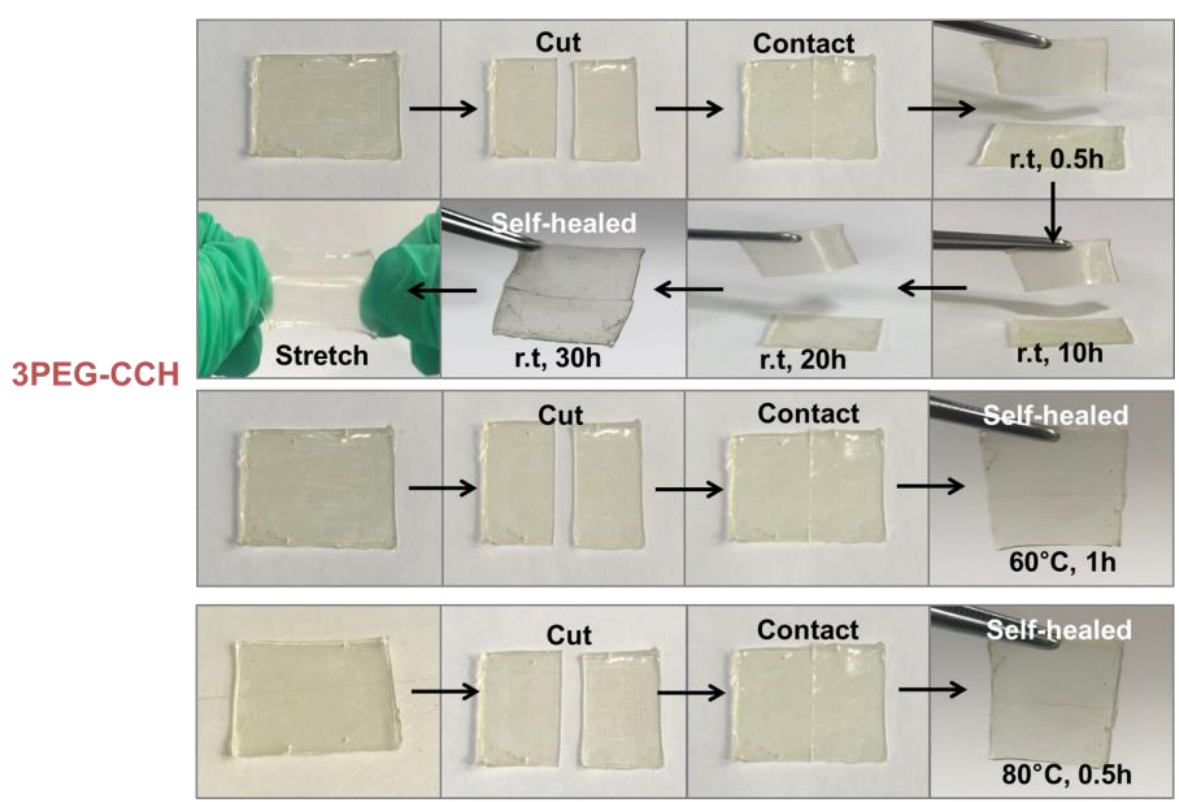

Figure S6. Optical images showing the self-healing process of 3PEG-CCH polymer electrolyte at room temperature, $60{ }^{\circ} \mathrm{C}$ and $80{ }^{\circ} \mathrm{C}$. 


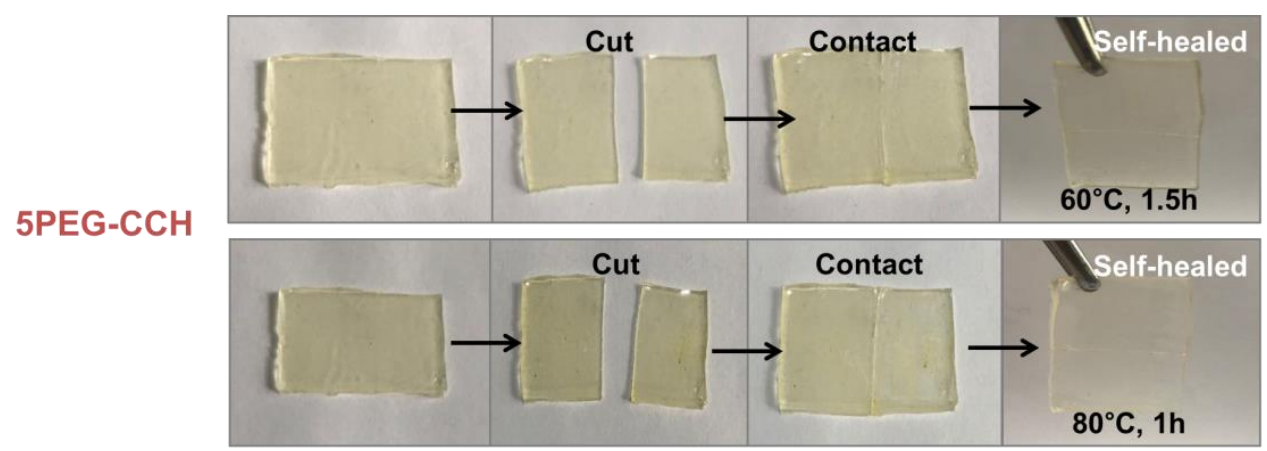

Figure S7. Optical images showing the self-healing process of the 5PEG-CCH polymer electrolyte at $60{ }^{\circ} \mathrm{C}$ and $80{ }^{\circ} \mathrm{C}$.

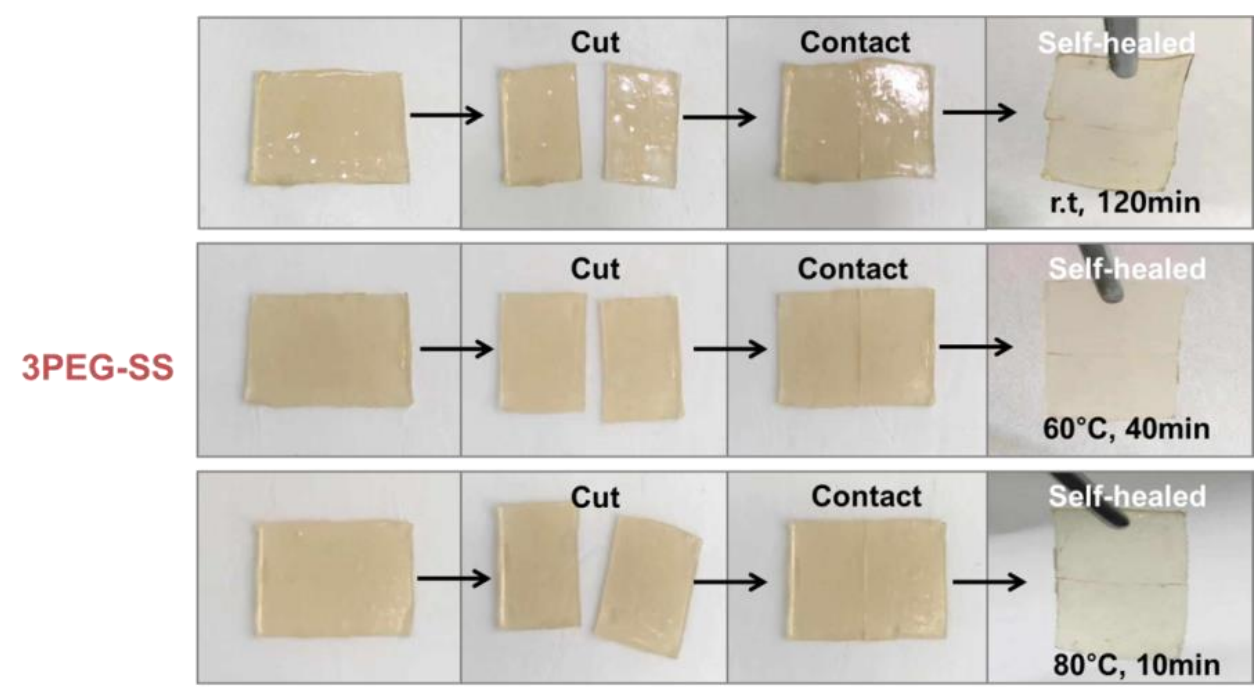

Figure S8. Optical images showing the self-healing process of the 3PEG-SS polymer electrolyte at room temperature, $60{ }^{\circ} \mathrm{C}$, and $80{ }^{\circ} \mathrm{C}$.

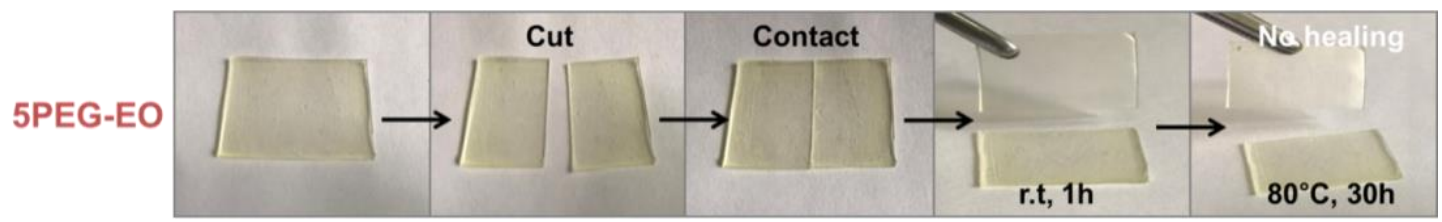

Figure S9. Optical images showing the self-healing process of the 5PEG-EO polymer electrolyte at room temperature and $80{ }^{\circ} \mathrm{C}$. 

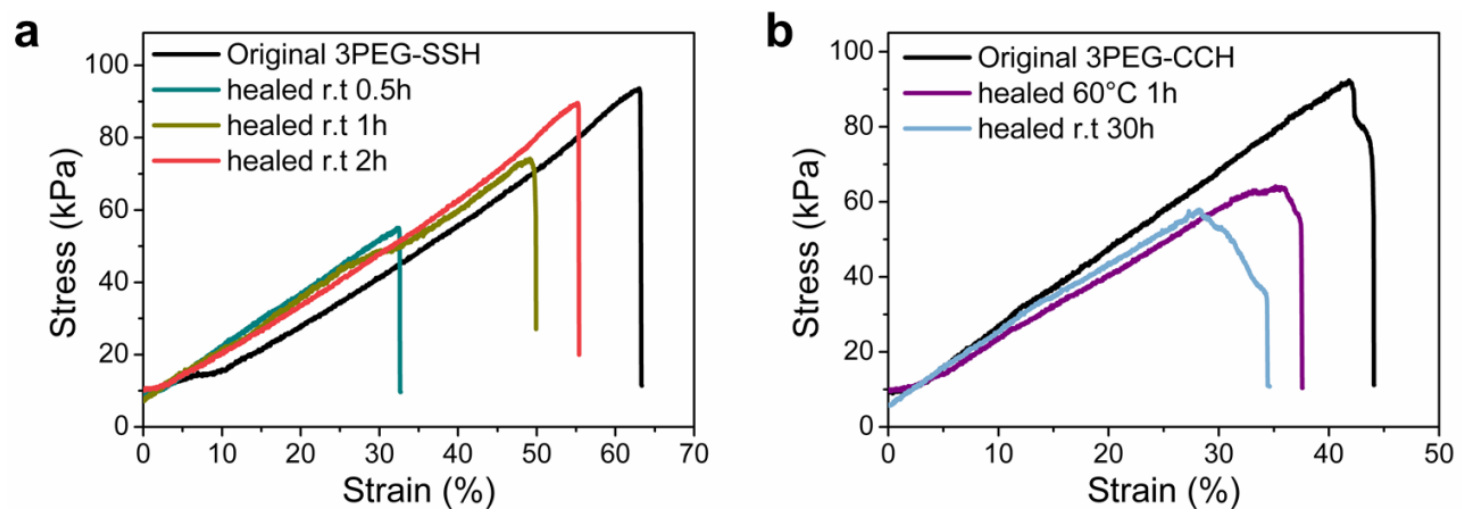

Figure S10. Stress-strain curves of the original and healed a) 3PEG-SSH and b) 3PEG-CCH polymer electrolytes.

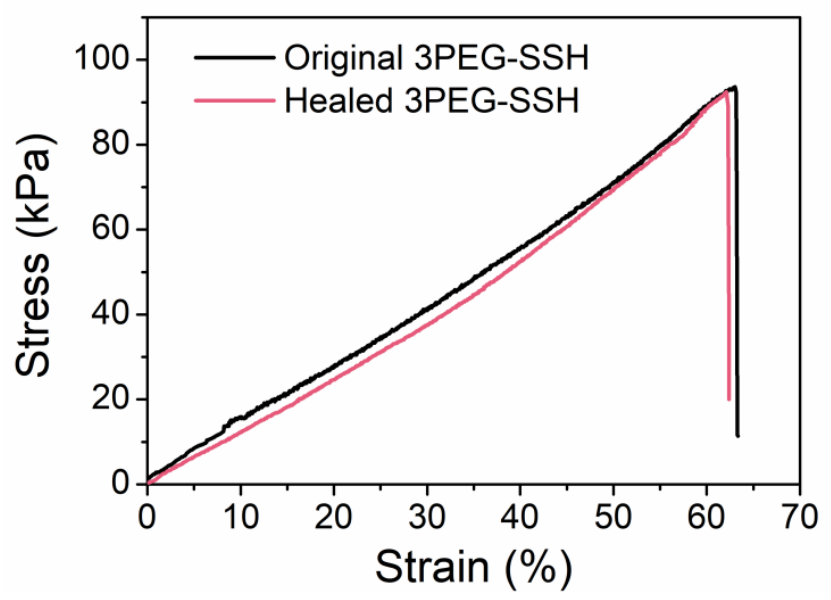

Figure S11. Stress-strain curves of the original and completely healed 3PEG-SSH electrolytes.

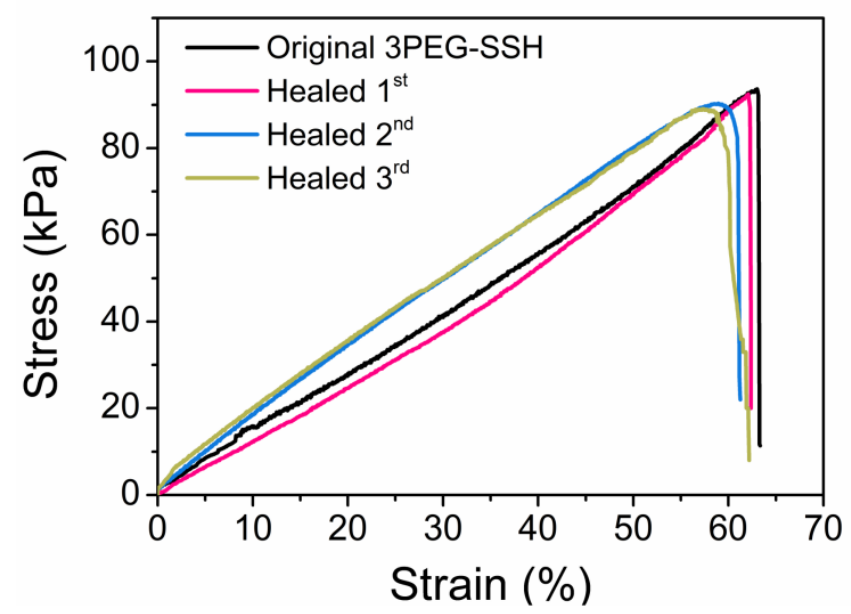

Figure S12. Stress-strain curves of 3PEG-SSH after multiple healing cycles. 
Table S1. The mechanical properties and healing efficiencies of the original and healed 3PEG-SSH and 3PEG-CCH polymer electrolytes.

\begin{tabular}{|c|c|c|c|c|c|c|c|c|c|c|c|c|c|}
\hline \multirow{3}{*}{ Samples } & \multicolumn{3}{|c|}{ Elongation at break (\%) } & \multicolumn{4}{|c|}{ Tensile strength $(\mathrm{kPa})$} & \multicolumn{6}{|c|}{ Healing efficiencies (\%) } \\
\hline & \multirow[t]{2}{*}{ Original } & \multirow[t]{2}{*}{$0.5 \mathrm{~h}$} & \multirow[t]{2}{*}{$2 \mathrm{~h}$} & \multirow[t]{2}{*}{ Original } & \multirow[t]{2}{*}{$0.5 \mathrm{~h}$} & \multirow[t]{2}{*}{$1 \mathrm{~h}$} & \multirow[t]{2}{*}{$2 \mathrm{~h}$} & \multicolumn{3}{|c|}{$\begin{array}{c}\text { Elongation at break } \\
(\%)\end{array}$} & \multicolumn{3}{|c|}{$\begin{array}{c}\text { Tensile strength } \\
(\mathrm{kPa})\end{array}$} \\
\hline & & & & & & & & $0.5 \mathrm{~h}$ & $1 \mathrm{~h}$ & $2 \mathrm{~h}$ & $0.5 \mathrm{~h}$ & $1 \mathrm{~h}$ & $2 \mathrm{~h}$ \\
\hline 3PEG-SSH & 63 & 32.5 & 55 & 93 & 55 & 74 & 89 & 51.6 & 77.9 & 87.4 & 59.4 & 79.4 & 95.7 \\
\hline \multirow{3}{*}{ 3PEG-CCH } & \multirow[t]{2}{*}{ Original } & \multirow[t]{2}{*}{ r.t, $30 \mathrm{~h}$} & \multirow{2}{*}{$\begin{array}{c}60{ }^{\circ} \mathrm{C}, \\
1 \mathrm{~h}\end{array}$} & \multirow[t]{2}{*}{ Original } & \multirow[t]{2}{*}{ r.t, $30 \mathrm{~h}$} & \multirow{2}{*}{\multicolumn{2}{|c|}{$60^{\circ} \mathrm{C}, 1 \mathrm{~h}$}} & \multicolumn{3}{|c|}{$\begin{array}{c}\text { Elongation at break } \\
(\%)\end{array}$} & \multicolumn{3}{|c|}{$\begin{array}{c}\text { Tensile strength } \\
(\mathrm{kPa})\end{array}$} \\
\hline & & & & & & & & r.t, 3 & & $\mathrm{C}, 1 \mathrm{~h}$ & r.t, $30 \mathrm{~h}$ & & ${ }^{\circ} \mathrm{C}, 1 \mathrm{~h}$ \\
\hline & 41.9 & 28.3 & 35.8 & 91 & 57 & & 3 & 67. & & 5.4 & 62.6 & & 59.2 \\
\hline
\end{tabular}

a

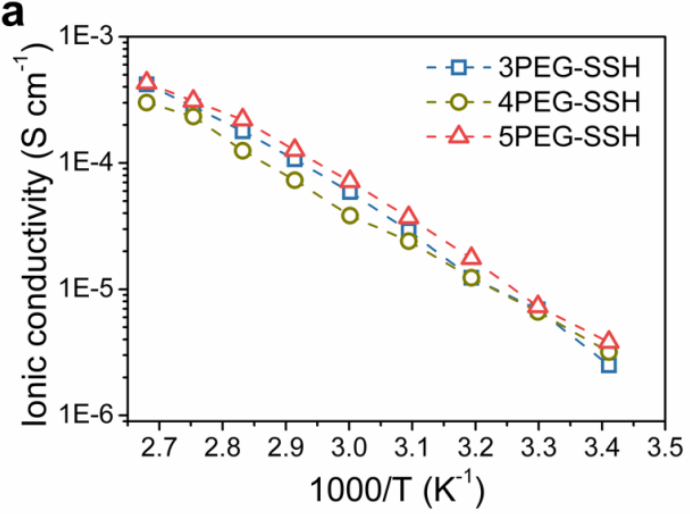

C

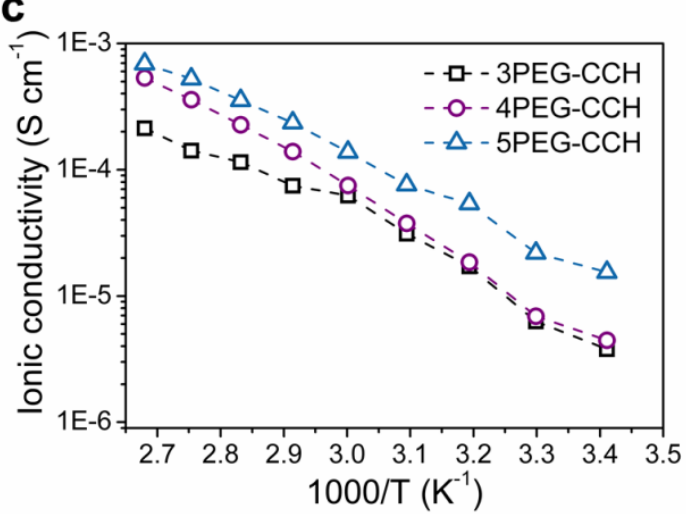

b

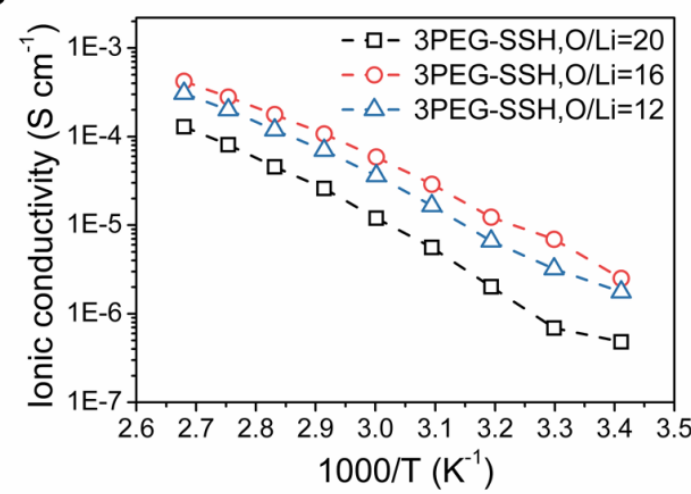

d

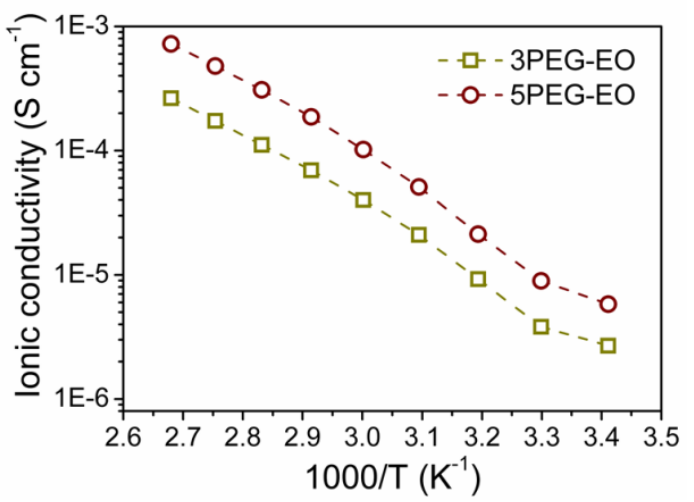

Figure S13. Ionic conductivities of a) PEG-SSH polymer electrolytes with different PEG content as a function of temperature, b) different of lithium salt content with 3PEG-SSH polymer electrolyte, c) PEG-SSH polymer electrolytes, and d) PEG-EO polymer electrolytes with different PEG content.

Figure S13c shows the ionic conductivities of $\mathrm{CCH}$ cross-linked polymer electrolytes (PEG-CCH) with different PEG content. The ionic conductivities of 3PEG-CCH, 4PEG-CCH and 5PEG-CCH electrolytes are $6.3 \times 10^{-6}, 6.9 \times 10^{-6}$, and $2.19 \times 10^{-5} \mathrm{~S} \mathrm{~cm}^{-1}$ at $30{ }^{\circ} \mathrm{C}$, 
respectively. As this result, the ionic conductivity values gradually increase with the addition of PEG content. The 5PEG-CCH electrolyte exhibits higher ionic conductivity than that of 5PEG-SSH electrolyte, when PEG content is the same. It can be explained that the high conductivity value of 5PEG-CCH electrolyte is attributed to the reduced crystalline phase of the polymer chain. Figure S13d shows the ionic conductivities of the PEGDMA cross-linked electrolyte. The ionic conductivity of 5PEG-EO reaches with value of $8.96 \times 10^{-6} \mathrm{~S} \mathrm{~cm}^{-1}$ at $30{ }^{\circ} \mathrm{C}$ and $3.09 \times 10^{-4} \mathrm{~S} \mathrm{~cm}^{-1}$ at $80{ }^{\circ} \mathrm{C}$. The low $T_{\mathrm{g}}$ value leads to an increase of ion transport between polymer matrix and lithium ion.
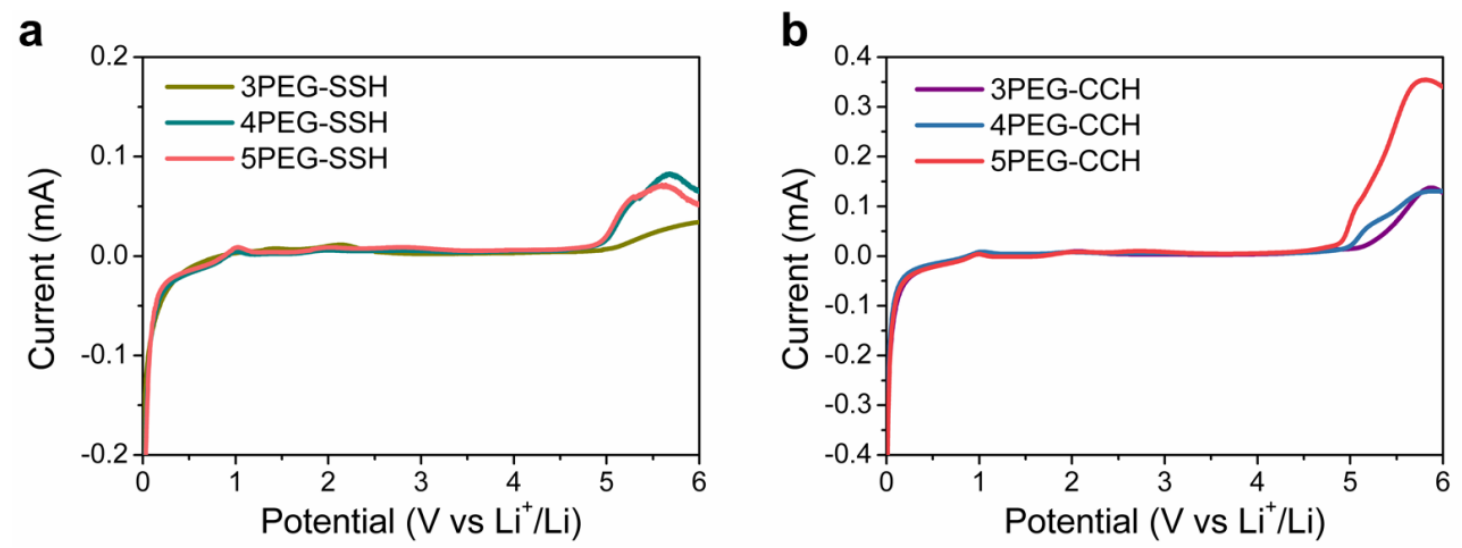

Figure S14. The electrochemical window of the a) PEG-SSH polymer electrolytes and b) PEG-CCH polymer electrolytes.

Figure S14a shows the LSV curves of PEG-SSH polymer electrolyte with different PEG contents. The oxidative decomposition potentials of 5PEG-SSH and 4PEG-SSH are around 4.91 $\mathrm{V}$ and $4.96 \mathrm{~V}$ vs $\mathrm{Li}^{+} / \mathrm{Li}$, respectively. As displayed in Figure $\mathbf{S 1 4 b}$, the oxidative decomposition potential of $5 \mathrm{PEG}-\mathrm{CCH}$ is around $4.5 \mathrm{~V}$, and $4 \mathrm{PEG}-\mathrm{CCH}$ is $4.82 \mathrm{~V}$. The presence of cross-linked in the electrolyte matrix enhanced the oxidation stability. These results demonstrate that the cross-linked polymer electrolytes can be applied in LIBs at a high voltage. 


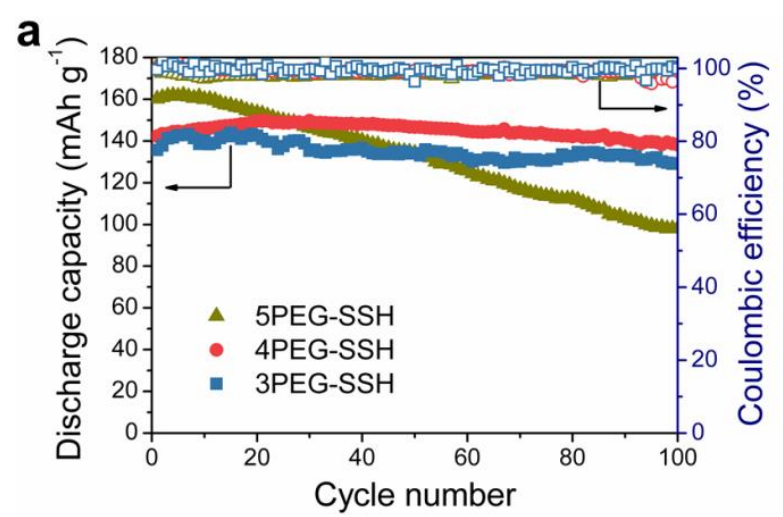

Figure S15. Cycling performances of

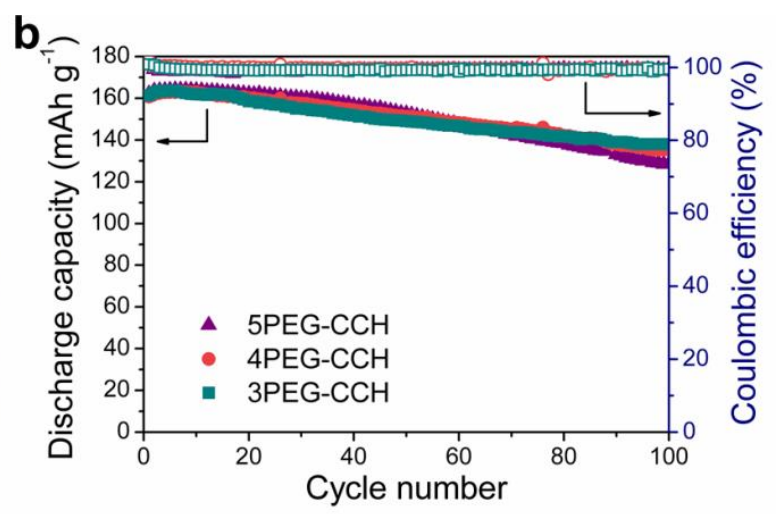

a) $\mathrm{Li} / \mathrm{PEG}-\mathrm{SSH} / \mathrm{LiFePO}_{4}$ cells and b) $\mathrm{Li} / \mathrm{PEG}-\mathrm{CCH} / \mathrm{LiFePO}_{4}$ cells evaluated with a current density of $0.1 \mathrm{C}$ at $60{ }^{\circ} \mathrm{C}$.

Figure S15 illustrates the long cycling performance of PEG-SSH and PEG-CCH batteries with different cross linker contents at a current rate of $0.1 \mathrm{C}$ at $60{ }^{\circ} \mathrm{C}$. The $5 \mathrm{PEG}-\mathrm{SSH}$ and 4PEG-SSH cells exhibit an initial discharge capacity of $160.9 \mathrm{mAh} \mathrm{g}^{-1}$ and $141.5 \mathrm{mAh} \mathrm{g}^{-1}$, respectively. All of the PEG-CCH electrolytes have similar initial discharge capacities (about $\left.160 \mathrm{mAh} \mathrm{g}^{-1}\right)$. The discharge capacity of 5PEG-SSH cell maintained at $98 \mathrm{mAh} \mathrm{g}^{-1}$ after 100 cycles, which represents lower capacity retention of $61.3 \%$ and the discharge capacity of the 4PEG-SSH cell was maintained $138.3 \mathrm{mAh} \mathrm{g}^{-1}$ after 100 cycles with increase content of disulfide bonds, which represents capacity retention of $97.2 \%$. In contrast, the cycle performance of PEG-CCH batteries exhibited at a current rate of $0.1 \mathrm{C}$ at $60{ }^{\circ} \mathrm{C}$. The discharge capacities of the 5PEG-CCH and 4PEG-CCH were 128.5 and $135.4 \mathrm{mAh} \mathrm{g}^{-1}$ after 100 cycles, respectively, which exhibits capacity retention of $79.2 \%$ and $84.2 \%$, respectively.

Overall, these results could be seen that the cells with high content of cross-linker are more stable, and that the cells with disulfide bonds have higher capacity retention. As shown in Figure S16, the difference of discharge voltage plateaus of 3PEG-SSH is lower than that of 3PEG-CCH. The cyclic voltammogram $(\mathrm{CV})$ result also exhibited that the reduction peak of 3PEG-CCH cell was higher than 3PEG-SSH cell (Figure S17). Thus, it can be demonstrated that the lower the discharge voltage plateaus as the lower the reduction peak of CV. 


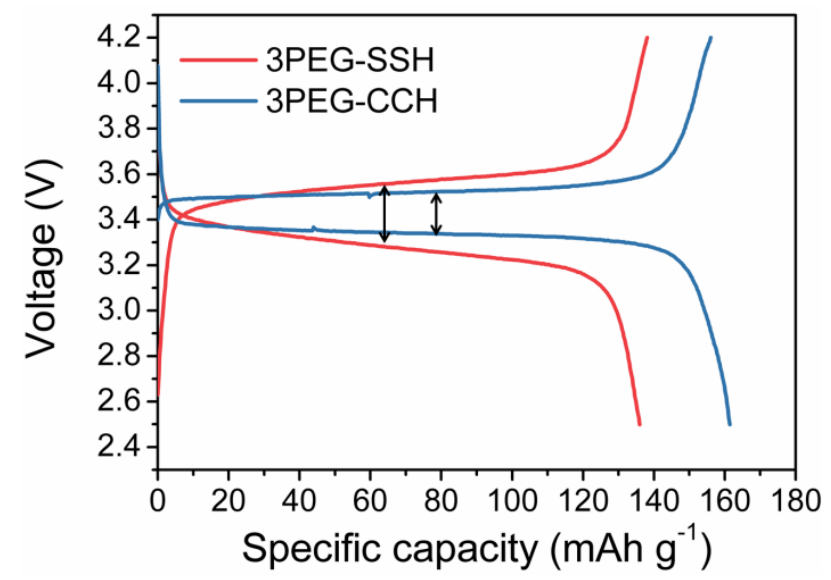

Figure S16. Initial charge-discharge curves of 3PEG-SSH and 3PEG-CCH polymer electrolytes under $0.1 \mathrm{C}$.

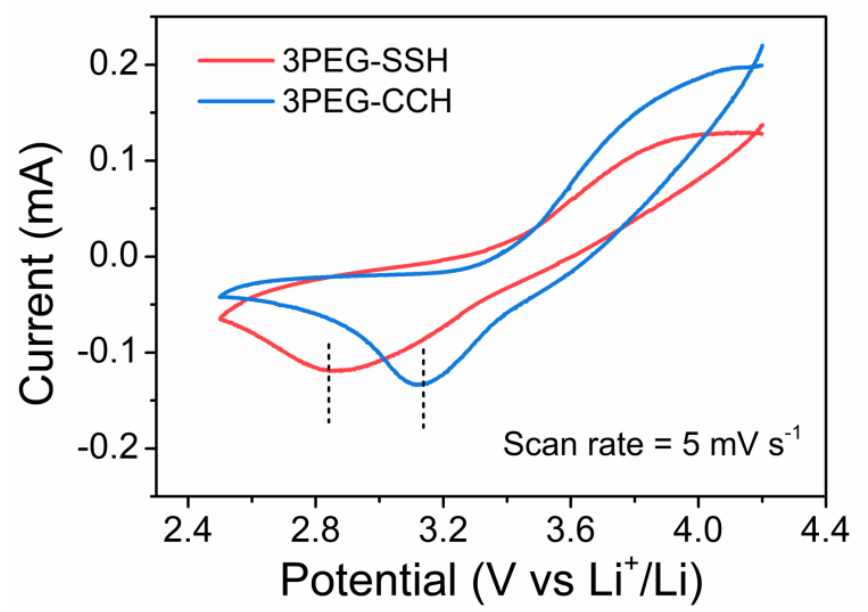

Figure S17. Cyclic Voltammetry curves of 3PEG-SSH and 3PEG-CCH polymer electrolytes were measured in asymmetrical $\mathrm{Li} / \mathrm{SHSPEs} / \mathrm{LiFePO}_{4}$ coin cell at scan rate of $5 \mathrm{mV} \mathrm{s}^{-1}$. 